\title{
Design of Multimedia Teaching Platform for Chinese Folk Art Performance Based on Virtual Reality Technology
}

\author{
https://doi.org/10.3991/ijet.v12.i09.7487 \\ Hong Li \\ University of Science and Technology Liaoning, Anshan, Liaoning \\ $15841293299 @ 163 . \mathrm{com}$
}

\begin{abstract}
Virtual reality (VR) technology can bring us immersive, so it can be widely applied in all professions and trades. The application of multimedia in Chinese folk art performance teaching has many problems and defects, and VR technology can help overcome such problems and defects. This paper aims to develop and design multimedia teaching with VR technology from the aspects of system structure, system function, system multimedia, and system implementation based on the defects in the course of Chinese Folk Art Performance, to combine virtual situations created with VR technology with the teaching of Chinese folk art performance, and decompose classic teaching cases. Contrast experiment shows that the VR-based multiple teaching systems is helpful for students to improve their theoretical knowledge reserve and enhance students' self-regulation of learning, arouse students' learning interest, and improve classroom atmosphere. These findings indicate this teaching design can help students comprehend the teaching contents of Chinese folk art performance, and improve students' learning ability and efficiency.
\end{abstract}

Keywords-VR technology, teaching of Chinese folk art performance, teaching design, multimedia

\section{Introduction}

Multimedia teaching has good effect, and has become a teaching method widely applied in modern times. But multimedia teaching also has shortcomings in the field of Chinese folk art performance teaching. (1) Chinese folk art performance is not included into the scope of liberal education in the current sequence of higher education subjects[1]; (2) The teaching contents are obsolete, and the key to learning of Chinese folk art performance rests in practice and interaction of performance; (3) The main teaching mode of Chinese folk art performance is that teacher dominates in classroom teaching, and students passively receive knowledge, in which students are less initiative and show little interest in the learning of Chinese folk art performance[2]. Due to these problems, multimedia teaching is mainly applied for extensive teaching, and cannot meet the need of teaching students in accordance of their foun- 
dation and learning ability of the subject of Chinese folk art performance. Thus, a high teaching efficiency cannot be achieved via multimedia teaching.

VR is an acronym of Virtual Reality. The concept was put forward in the early 1980s. Specifically, it refers to a new man-machine interaction means created by the aid of computer and the latest sensor technology. VR technology [3] relates to various different subjects, and can be expressed in various vivid patterns, be used to fully reflect the teaching contents of various subjects, and create lifelike simulation situation developing with teaching requirements, to help students improve the efficiency of grasping knowledge and skills, optimize teaching process and raise teaching quality. Considering the problems of applying multimedia teaching for the course of Chinese folk art performance as set out above, this paper aims to develop and design a multimedia teaching method of Chinese folk art performance based on VR technology, to combine VR technology with Chinese folk art performance, and discuss the function of interaction between reality teaching and VR situation in the improvement process of multimedia teaching of Chinese folk art performance.

\section{State of the art}

VR technology can bring us immersive, so it can be widely applied in all professions and trades. Saritas et al [4] applied VR technology in chemistry education, having created a desktop virtual reality technology for molecular geometry learning. The results show that perceived usefulness and perceived ease of use have a positive effect on the behavioral intention to use VR tool. Moreover, the findings indicated that chemistry teacher candidates agreed that VR technology is helpful to facilitate understanding, allow to learn fast, enhance the motivation, and ease thinking schematically. Some researchers [5] proposed to apply VR technology in civil engineering teaching, and the results suggested that VR technology was proved via practice to be useful to improve students' learning efficiency. VR has been being a hot spot in the scientific and technological circles all around the world in recent years. It can address the needs of scenario and natural interaction of learning media, and has a broad application prospect in education field, such as staff training [6], medical education [7], and, especially, art education. Art creators can create a three-dimensional space with VR equipment; VR technology is helpful to develop teaching methods. Teacher can expand teaching method from planar projection to virtual wandering, to enhance teaching immersive. However, according to the results of applying VR technology in art education, the art development and technological development of VR technology in China are inharmonious, and the application of VR technology in art field relatively lags behind. For the teaching of some traditional subjects in China, such as Chinese folk art performance, traditional multimedia projection is still the main teaching means [8]. Chinese folk art forms mainly consist of folk song and dance, telling and singing, and burlesque, were originated from primitive songs and dances, are a comprehensive stage art pattern with a long history, integrate literature, music, dance, fine arts, martial arts, acrobatics, and performance arts, and can be classified into more than 360 types [9]. 
Many Chinese universities lay much stress on art courses, and cultivation of students' artistic accomplishment. From the aspect of content, most of previous researches on this field are about basic theories, and overlap with each other. There are few researches on regional, type and targeted application of VR technology, let alone thematic research on the application of VR technology in art education at college and university. Li [10] et al. put forward a design method suitable for multimedia vocal music teaching, which helps improve the intuition and interactivity of vocal music teaching, and increase the interestingness of vocal music teaching. The Academy of Traditional Chinese Opera [11], based on media resources and campus network system, constructed an application-oriented media asset management system for colleges and universities, having realized digital storage and utilization of multimedia resources of colleges and universities and raised the application effect in teaching. Presently, VR technology is mainly applied in the basic area of art teaching field. Specifically, only $3 \mathrm{D}$ models generated with VR technology are presented in teaching process, and few people make further expansion. Besides, in the field of Chinese folk art performance education, the traditional projection teaching method is still the main teaching method, interactive and experiential teaching is seldom performed, and the teaching efficiency is low [12]. Considering the current situation of relevant researches, this paper aims to innovatively combine VR technology with Chinese folk art performance education, and provide a Chinese folk arm performance teaching method and system based on AR graffiti technology, to combine AR graffiti technology with Chinese folk art performance teaching, and study the combination of college art education with VR technology. This paper provides a new direction of educational reform, of certain research value.

\section{Theoretical basis}

\subsection{VR technology}

VR technology is a new subject having been widely applied in various professions and trades in recent years. It essentially is a computer simulation system with which user can create and experience a virtual world. With VR technology, we can generate a lifelike three-dimensional simulation environment with the aid of computer, to realize interactive three-dimensional dynamic views integrating multisource information and system simulation of entity behaviors.

View refers to reproduction of scene realized with three-dimensional changes. Thus, besides optical problems, the actual calculations about object motion in space also should be tackled. This design, based on classical algorithm, is intended to adopt the improved algorithm of orthographic projection and back projection of cylindrical surface in accordance with the teaching requirements of Chinese folk art performance and the mechanism of human sight, as below:

$$
\partial=\operatorname{arctg}(x / r)
$$


In accordance with the formula of arc length $=$ radian $\times$ radius, then:

$$
x^{\prime}=r \partial=r \cdot \operatorname{arctg}(x / r)
$$

In accordance with the theorem that if triangle $O P^{\prime} P^{\prime_{1}}$ is similar to triangle $O P^{\prime} P^{\prime_{1}}, O P_{1}=\mathrm{r}$, and $O P_{1}=\mathrm{OP}=r / \cos \partial$, then $y^{\prime} / y=r / O P$

Then:

$$
\begin{gathered}
y^{\prime}=y \cdot r(r / \cos \partial)=y \cdot \cos \partial \\
\left\{\begin{array}{c}
\partial=\operatorname{arctg}(x / r) \\
x^{\prime}=r \cdot \partial \\
y^{\prime}=y \cdot \cos \partial
\end{array}\right.
\end{gathered}
$$

Formula (4) reflects the improved algorithm of cylindrical projection. Based on Formula (4), the back projection formula can be obtained, as below:

$$
\left\{\begin{array}{c}
x=r \cdot \operatorname{tg}\left(x^{\prime} / r\right) \\
y=y / \cos \partial \\
\partial=\operatorname{arctg}\left(x^{\prime} / r\right)
\end{array}\right.
$$

According to the projection and back projection formulas of cylindrical surface, we can project images to be spliced to cylindrical surface to realize view splice.

View simulation system consists of three parts: view database, image generator, and display system. Its image display principle is as shown in Fig. 1 Fig. 2 shows affect picture of stage for Chinese folk art performance constructed with VR technology.

A virtual model superimposed on a realistic scene
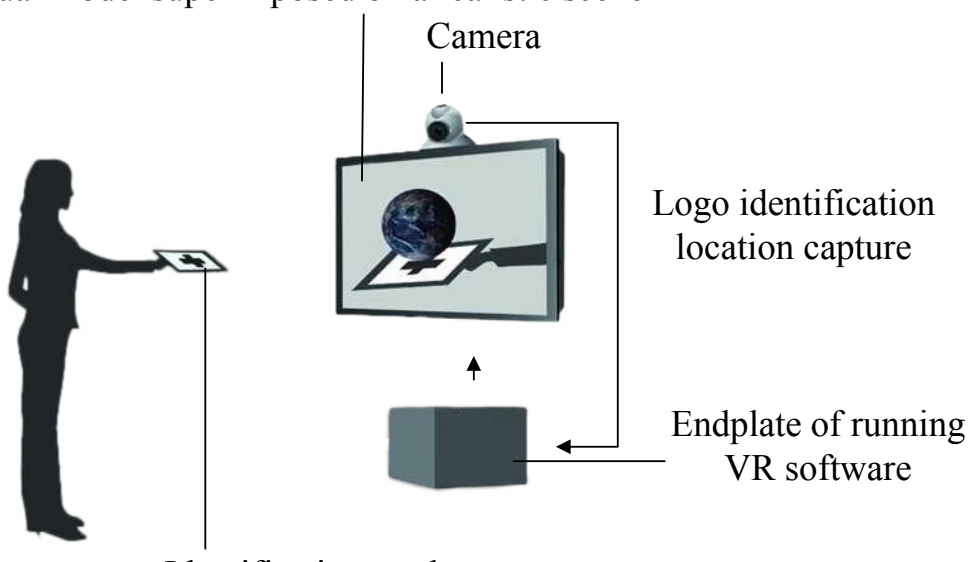

Identification mark

Fig. 1. Emulational view image generation principle 


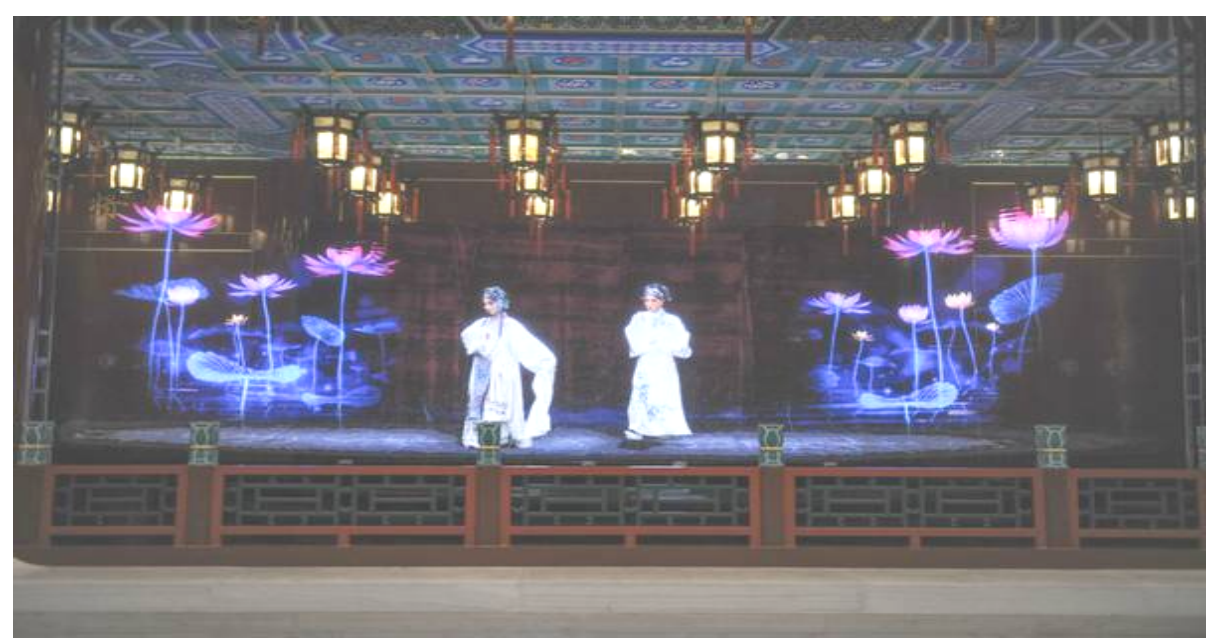

Fig. 2. Effect picture of stage for Chinese folk art performance constructed with VR technolo-

gy

According to Fig. 2, the Chinese folk art performance stage constructed with VR technology can be of various and abundant contents. Even in an art center with glass ceiling where it is bright in daytime, clear imaging still can be realized with VR technology. Chinese classical traditional opera is a comprehensive system that is broad, profound, and marvelous. The pace of life in modern times is fast, which, together with the problem of mode of transmission, makes opera containing Chinese traditional culture decline gradually. It is very pitiful. We can capture life-size pictures with VR technology. After picture taking, our first job is to store digital high definition stereoscopic images, and then we should solve the problem of image copy. By this, opera performance can be realized in different places as movie. Especially, it can be applied for holding activities for celebrating the Spring Festival overseas to realize that true and virtual audiences appear together. Moreover, there are abundant techniques of expression of VR technology. In opera performance, various games also can be designed for interaction, to attract more young people.

\subsection{Technologies for multimedia teaching development}

The VR-based Chinese folk art performance teaching system designed and implemented in this paper is to be implemented in Web environment, and is of B/S structure. User can access to the system via IE browser at client end. The design interface is friendly.

B/S architecture. B/S (Browser/Server) architecture consists of browser and server. $\mathrm{B} / \mathrm{S}$ architecture is a program structure based on browser and server running on IIS service information manager. It is a popular program structure [13]. B/S architecture has solved the problem that program cannot access to the Internet. With such an architecture, the right of using the system can be realized at any place by deploying and configuring the server. 
Net frame and development environment. In .Net environment, a unified Internet standard (such as XML) is applied to link different systems together, "alliancetype" supervisory program is implemented to manage active service programs, and a powerful security protection backend is provided for the programs. .NET Framework [13] is a software development platform launched by Microsoft, which mainly supports C\# language.

Database technology. In accordance with the technical requirements of the system and out of other considerations, it is planned to select the prevailing second generation of database system based on rational data model for the design. The theories of this type of database products have been completely matured, which can be highly compatible with various Windows operating systems of Microsoft, and used for building a distributed browser/server mode. Thus, it has become the first choice for data solution to education information management with rational database management system as the core.

C\# language. As an advanced object-oriented programming language running on .NET Framework launched by Microsoft, it was evolved from "C language" and "C++ language", and has both the high data operation efficiency of $\mathrm{C}++$ language, and the cross platform capability of Java language.

\section{Multimedia Teaching Platform for Chinese Folk Art Performance Based on Virtual Reality Technology}

\subsection{System structure design}

The characters of the teaching mode of VR-based Chinese folk arm performance decide that the art course education network platform must be designed in the principles of integrity and maturity, and it must be ensured that the system is highly stable, flexibly opened, and is good for actual operation. The mode of information transmission among modules of data flow display system is the soul of the system. The overall data flow chart of the system is as shown in Fig. 3. User logs in by entering user ID and password, the system acquires user right and guides the user to the right operation interface, and the user conduct corresponding functional operations, and logs out the system after finishing operation.

\subsection{System function design}

The VR-based Chinese folk art performance multimedia teaching system mainly consists of teacher console, microphone, and recording device. Besides, each of the teacher and students is provided with one pair of VR glasses respectively for interaction in the simulation environment. The scanner set on the master station is for scanning paper materials, such as dialogue, playscript with stage directions, background information, and so on, which will be transmitted to the display of all students via the master controller and master distributor. 


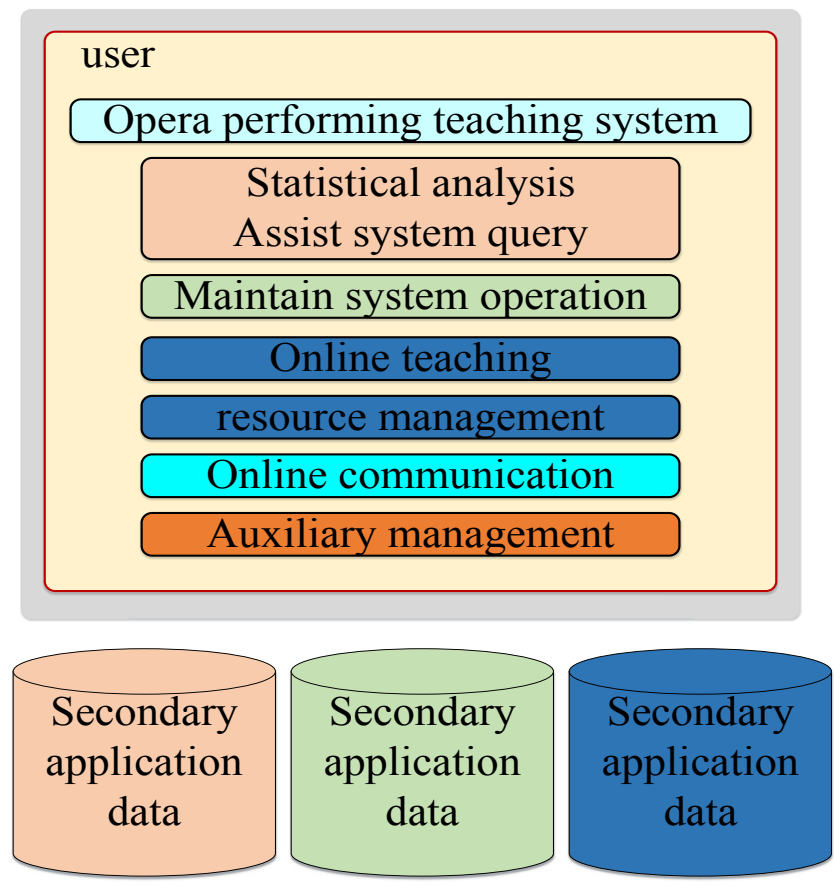

Fig. 3. Overall data flow chart of VR technology in the multimedia system of Chinese folk art performance

Please see Fig. 4 for the job control flow chart of the VR-based Chinese folk art performance multimedia teaching system, as below:

Capture. It is to capture teacher's or students' performance with camera, and decompose the captured performance fragment.

Match. It is to search a performance environment model matching with the captured performance fragment. The database is set with multiple recognizable performance fragments required for different teaching scenarios and 3D models of the corresponding performance environments, so that recognized fragments can be compared with that stored in the database, to identify the corresponding model on this basis.

Split and play. It is to call and play the wanted Chinese folk art form performance environment model. User can click the screen of the intelligent model terminal. The terminal will call and play the required music material once detects the click operation, and play the background music and 3D performance model synchronically, namely combining VR performance environment with performance music to achieve a lifelike teaching effect of "3D stage". Meanwhile, the play module also provides fragments of classical Chinese art form performance for simulation and study. User can click the screen to select the fragments to be simulated, the program installed in the intelligent terminal will combine user's performance with the environment to generate video, and play the simulation environment with the aid of VR glasses, which is for user to play back and make summarization. Fig. 5 shows effect picture of the VR-based Chinese folk art performance multimedia teaching system. 


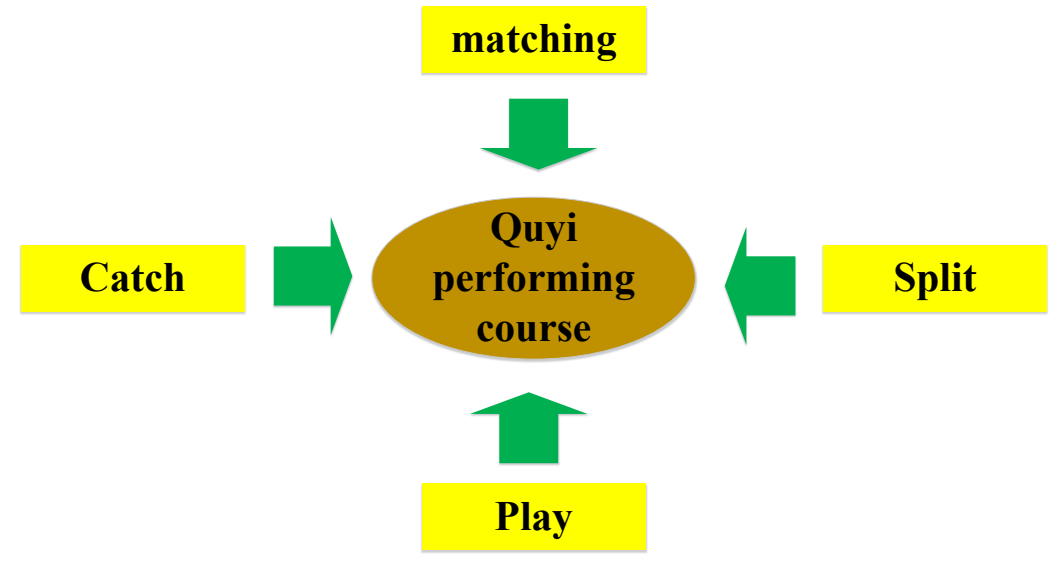

Fig. 4. Structure chart of VR-based Chinese folk art performance multimedia teaching system

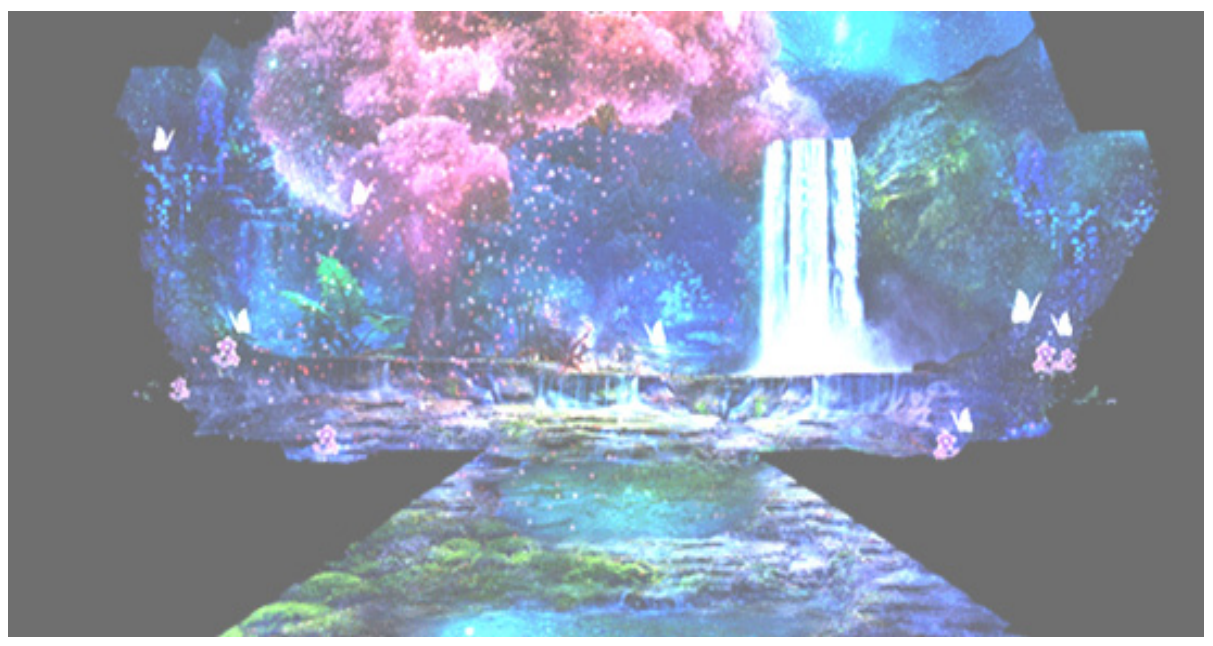

Fig. 5. Effect picture of VR-based Chinese folk art performance multimedia teaching system

\subsection{Database of VR-based Chinese folk art performance multimedia teaching system}

The core problem in in-process management of data and information of Chinese folk art performance course based on Microsoft SQL Server 2005 rational database is to adjust the relationship of the main data entities in accordance with the requirements and definition of system data. Please see Fig. 6 for the overall E-R diagram of the system. The main database entities include user entity (including Chinese folk art performance teacher, administrator and students), class entity, Chinese folk art performance course resource entity, training entity, and assignment entity. Meanwhile, the data definition, attributes and correlation of each entity should be analyzed from the perspective of functional requirement data. 


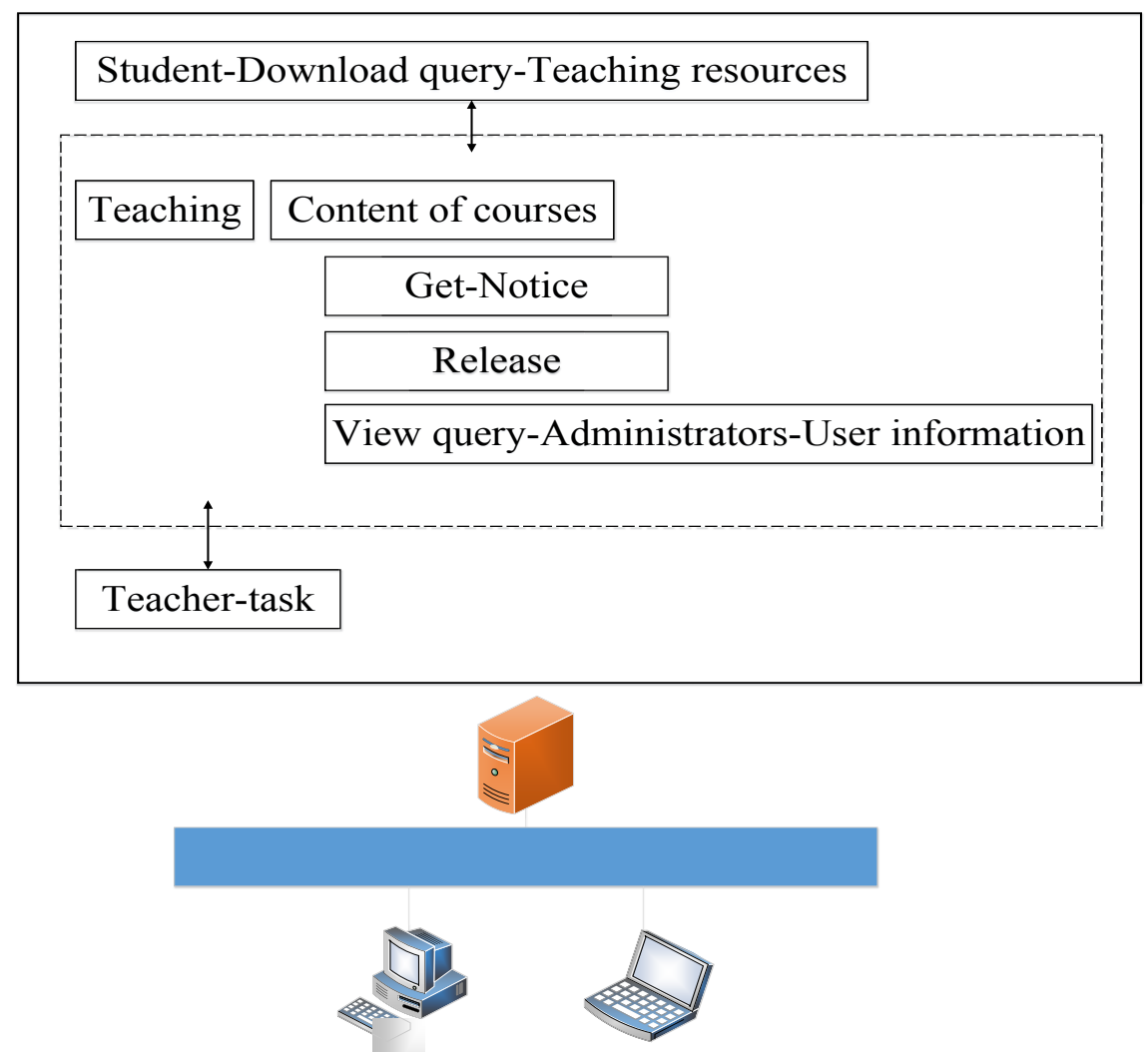

Fig. 6. Overall E-R diagram of VR-based Chinese folk art performance multimedia teaching system

\subsection{System implementation}

Login and management module. Accessing to the database for storage and operation is a necessary link of operation of the function module of this system, for which the sequence chart for user login should be followed. The core implementation submodule of the management module function of the system is user management. User management is mainly operated by the system administrator after logging in the system. The system administrator can perform core operation for system administration via the following rights, including user group management (add, delete, freeze and unfreeze), operation management, operating authorization management (setting of role permission), and user management (add, delete, change password and initialize passwords of other users), while other users can change their passwords only.

Teacher user module. For teacher user module, RCP technology is adopted. To enhance the system performance, a distributed architecture is adopted. Teacher user module shares the same database with student user and administrator user, but enjoys different services. Such a design has largely improved user experience. Please see Fig. 7 for the diagram of teacher user module. 
The multimedia teaching system of VR technology "course of Quyi" Teacher side operating system

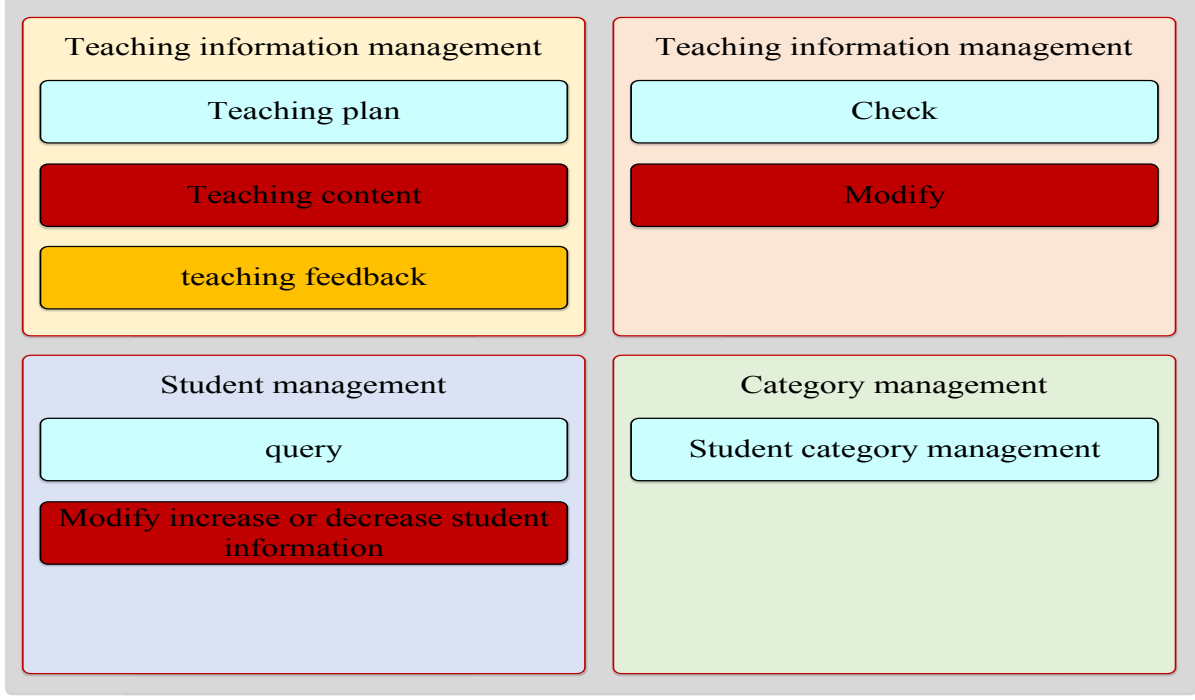

Fig. 7. Operation architecture diagram of teacher user module

Besides, all teaching materials in the resource management sequence of teacher $\mathrm{u}-$ ser module are arranged by layer according to the directory tree, and the subfolders also are arranged in the same way. In the case that the arrangement types are the same, an inverted order is followed. Thus, the latest resources are placed at the top. The available browse modes include thumbnail and list, between which switch can be made. The system will automatically record the data on users' operations of downloading and browsing learning resources.

Student user module. The student user module mainly consists of teaching information management, local resource management, and personal information management, which can address student users' needs of viewing learning resources (videos and images) of Chinese folk art performance, and managing personal information and personal videos.

\subsection{Effect check}

To check the effectiveness of this teaching design, we carried out an experiment over the excellent course of Chinese folk art performance of the class of Grade 2015 of the specialty of dramatic performance. 100 students (39 boys and 61 girls) were sampled from two classes (50 students per class) of Grade 2015. The experimental period is one semester. The 100 students were divided into two groups equally, an experimental group and a control group. The two groups employed the same teaching materials. But traditional teaching method was implemented for the control group, while the VR-based Chinese folk art performance multimedia teaching system was implemented for the experimental group to realize interactive learning. 
At the end of the experimental period, a questionnaire survey was carried out on the comments of the two groups on the teaching modes. The collecting rate of questionnaire reached $100 \%$. The questionnaire covers independent learning ability, learning interest, active classroom atmosphere, and performing capacity improvement. A comparison of the results of final theory test was made between the two groups by grading the results at four levels, namely excellent (90-100 scores), good (80-89 scores), average (60-79 scores) and bad (0-60 scores). The results of the survey and the comparison are shown in table 1 and table 2.

Table 1. Comparison of results of final theory test of the two groups $(\mathrm{N}=100)$

\begin{tabular}{|l|c|c|c|c|c|}
\hline \multicolumn{1}{|c|}{ Group } & excellent & good & commonly & Poor & Excellent rate \\
\hline Experimental group $(\mathrm{N}=50)$ & 18 & 21 & 8 & 3 & $78 \%$ \\
\hline Control group $(\mathrm{N}=50)$ & 11 & 19 & 14 & 6 & $60 \%$ \\
\hline
\end{tabular}

Table 2. Comments of the two groups on teaching methods $(\mathrm{N}=100)$

\begin{tabular}{|l|c|c|c|c|}
\hline \multicolumn{1}{|c|}{ Group } & $\begin{array}{c}\text { Self-regulation } \\
\text { of learning }\end{array}$ & $\begin{array}{c}\text { Arouse learn- } \\
\text { ing interest }\end{array}$ & $\begin{array}{c}\text { Enhance classroom } \\
\text { atmosphere }\end{array}$ & $\begin{array}{c}\text { Improve per- } \\
\text { forming capacity }\end{array}$ \\
\hline Experimental group $(\mathrm{N}=50)$ & 32 & 29 & 30 & 33 \\
\hline Control group $(\mathrm{N}=50)$ & 24 & 21 & 19 & 21 \\
\hline
\end{tabular}

According to Table 1, the VR-based multiple teaching system is helpful for students to improve their theoretical knowledge reserve; besides, as shown in Tab. 2, it is also helpful to enhance students' self-regulation of learning, arouse students' learning interest, and improve classroom atmosphere, but there is still a large space for progress, which is because that the independent learning ability of the students who had received traditional "duck-stuffing" teaching mode for a long time has not been fully developed. It is worth noting that more than half of the students had got largely improved in performing capacity after receiving experiment teaching.

\section{Conclusions}

VR-based multimedia teaching is a development tendency of Chinese folk art performance in future, and the immersive, interaction and imagination of VR technology makes VR-based multimedia teaching be of great application value in the education field. Experimental research shows that the VR-based multimedia teaching system is helpful to improve teaching efficiency, and students' learning initiative and independent learning ability. It integrates various modern advanced multimedia teaching techniques and is combined with basic classroom teaching, providing interesting teaching mode to attract students to train their artistic creativity. VR technology aided teaching plays an important role in modern classroom teaching, which cannot be ignored. But computer technology can never replace the traditional classroom teaching. Meanwhile, the application of VR technology makes teaching more demanding for teachers. Teachers are required to master advanced computer technology, fully under- 
stand the essence of modern education, grasp teaching objectives, focal points and difficult points, and understand the advantages and limitations of traditional teaching mode, so as to apply the advantages of traditional teaching mode in modern teaching and make up the deficiency. For art specialty, more stress should be laid on the application of advanced computer aided teaching technology, which can provide abundant resources for our teaching activities and help us have teaching activities in a vivid way.

\section{Acknowledgment}

This work was supported in part by the Scientific research project of Liaoning Provincial Education Department (2016FRPY06) and youth special fund project of University of Science and Technology Liaoning (2015QN26).

\section{$7 \quad$ References}

[1] Schultheis, M.T., \& Rizzo, A.A. The application of virtual reality technology in rehabilitation. Rehabilitation Psychology, 2001, vol. 46(3), pp. 296-311. https://doi.org/10.1037/ 0090-5550.46.3.296

[2] Jiang, Y. The mode construction of drama teaching. Yinyue Shenghuo, 2017, vol. 4(1), pp. 71-72.

[3] Zhang, C.L. High school, drama appreciation, teaching strategy. Northern Music, 2014, vol. 11(11), pp. 109-109.

[4] Saritas, M.T. Chemistry Teacher Candidates' Acceptance and Opinions about Virtual Reality Technology for Molecular Geometry. Educational Research \& Reviews, 2015, vol. 10(20), pp. 2745-2757. https://doi.org/10.5897/ERR2015.2525

[5] Sampaio, A.Z. Virtual Reality Technology Applied in Teaching and Research in Civil Engineering Education. Journal of Information Technology \& Application in Education, 2012, vol. 1(4), pp. 152-163.

[6] Komura, T., Lau, R.W., Lin, M.C., et al. Virtual reality software and technology. IEEE Computer Graphics \& Applications, 2015, vol. 35(5), pp. 20-21. https://doi.org/10.1109/ MCG.2015.102

[7] Li, F.Z. Liu, C.Y. Application of Visual Reality Technology Based on VR-Platform in Teaching. Science \& Technology Information, 2012, vol. 9, pp. 186-187.

[8] Chen, S. The effective use of multimedia means in drama teaching. China training, 2015, vol. 18 , pp. 42-42.

[9] Jiang, Y.D., Yoon, J.S. The stage aesthetics of Modern Opera under the new media technology. Xibu Guangbo Dianshi, 2016, vol. 17, pp. 17-17.

[10] Li, W.J., Zhang, W.J., Zhang, Y., et al. Research on the Interactive Multimedia Teaching System of Vocal Music. Microcomputer Applications, 2009, vol. 25(9), pp. 21-24.

[11] An, Y.L. Construct digital teaching platform and spread Chinese national culture -construction and application of digital teaching platform of Academy of Chinese Traditional Opera. Journal of National Academy of Chinese Theatre Arts, 2007, vol. 28(4), pp. 122-127. 
Paper-Design of Multimedia Teaching Platform for Chinese Folk Art Performance Based on Virtual..

[12] Hu, B., Deng, C., Ye, J. Design and Implementation of Visual Electronic Commerce Based on Browser/Server Architecture. Advanced Materials Research, 2011, vol. 271-273, pp. 336-339. https://doi.org/10.4028/www.scientific.net/AMR.271-273.336

[13] Rohr, C., Marwan, W., Heiner, M. Snoopy--a unifying Petri net framework to investigate biomolecular networks. Bioinformatics, 2010, vol. 26(7), pp. 974-975. https://doi.org/10.1093/bioinformatics/btq050

\section{Author}

Hong $\mathbf{L i}$ is an associate professor in the University of Science and Technology Liaoning, Anshan 114051, China (15841293299@163.com).

Article submitted 24 March 2017. Published as resubmitted by the author 20 June 2017. 